\title{
Synthesis, characterization and properties of amphiphilic block copolymers of 2-hydroxyethyl methacrylate and polydimethylsiloxane prepared by atom transfer radical polymerization
}

\author{
Serkan Bas ${ }^{1}$ and Mark D Soucek ${ }^{2}$
}

A series of amphiphilic poly(2-hydroxyethyl methacrylate)- $b$-polydimethylsiloxane- $b$-poly(2-hydroxyethyl methacrylate) (pHEMA$b$-PDMS- $b$-pHEMA) (A-B-A) triblock copolymers were synthesized with varying block molecular weights. Control over the polymerization, micellar size and size distribution, dynamic mechanical properties, and film morphology of nine triblock copolymers was investigated as a function of block length. The polymerization resulted in copolymers with polydispersity index below 1.5. The self-assembly behavior of the triblock copolymers was studied in selective solvents for $A$ and $B$ blocks. The micellar diameter was determined by dynamic light scattering and transmission electron microscopy. The film morphologies were investigated by small angle X-ray scattering. Phase separation was observed when the blocks had similar molecular weights (symmetry). However, the ordering of the morphology was disrupted when the blocks lengths were asymmetric. Phase separation was observed by atomic force microscopy when the block molecular weights were symmetric. The viscoelastic properties were examined using dynamic mechanical analysis. The modulus and crosslink density increased with increasing pHEMA content.

Polymer Journal (2012) 44, 1087-1097; doi:10.1038/pj.2012.86; published online 6 June 2012

Keywords: amphiphilic; ATRP; block copolymers; controlled polymerization; HEMA; polydimethylsiloxane; triblock copolymer

\section{INTRODUCTION}

Amphiphilic block copolymers are of great interest owing to their unique chemical structure. Amphiphilic block copolymers can form micelles in selective solvents, with soluble and insoluble segments forming the core and shell, respectively. Therefore, these copolymers can be used to stabilize colloids or in situations where their selfassembly capabilities might be useful. This allows block copolymers to be used to prepare nano- and micro-templates with controlled pore sizes. Several architectures can be prepared using amphiphilic block copolymers for applications such as coatings, inks, paints, textile, agriculture, cosmetics and biomaterials. ${ }^{1-5}$

The physical and chemical properties of amphiphilic copolymers, for example, the modulus ${ }^{3}$ and surface tension, ${ }^{6}$ can be adjusted by varying the block length, composition and architecture of the copolymer. These properties affect the morphology and critical micelle concentration (CMC). ${ }^{7}$ As the length of hydrophobic block increases, the CMC decreases. ${ }^{8}$ Varying the block characteristics allows for control over various polymer properties, such as crystallinity, glass transition, melting point and thermal degradation. 9 For example, the degree of swelling, optical transparency and mechanical properties of the block copolymers of poly(ethylene oxide) (PEO) and either poly( $\varepsilon$-caprolactone) or poly(L-lactic acid) depend on the hydrophobic polymer block type and polymer composition. ${ }^{10}$

Poly(2-hydroxyethyl methacrylate) is hydrophilic acrylic polymer with unique assets, including transparency, good mechanical properties and biocompatibility. The pHEMA hydroxyl groups can be crosslinked with melamine-formaldehyde (M-F) resins, isocyanates ${ }^{11}$ and epoxides. ${ }^{12}$ Flexible and high-gloss polymer films were prepared by curing 2-Hyroxyethyl methacrylate (HEMA)-modified polysiloxane. ${ }^{13}$ Polysiloxanes are widely used as leveling agents, flow promoters, lubricants for scratch control, defoamers and wetting agents for better spreading. ${ }^{14}$ Polysiloxanes have very low surface energy, low glass transition temperature, and thermal and oxidative stability. Polysiloxanes are hydrolyzable under mildly acidic or basic conditions. Mesoporous materials and membranes with controlled pore size can be prepared after etching polysiloxane. ${ }^{4,15}$ PDMS is biocompatible and oxygen permeable.

If the copolymers with pHEMA and PDMS are synthesized by controlled polymerization, the physical properties of the copolymer can be tuned more easily than if conventional free radical polymerization is used. Atom transfer radical polymerization (ATRP), a 
controlled free radical polymerization technique, has drawn significant attention due to the resultant ability to control molecular weight and polydispersity index (PDI) by the reversible halogen transfer between the active radical and the dormant alkyl halide in the presence of a transition metal catalyst. ATRP is more tolerant to impurities in the reaction medium than anionic polymerization is. The termination reactions in ATRP are insignificant because the concentration of radicalic species is low due to the significantly high deactivation rate. ${ }^{16}$

In this study, a series of poly(2-hydroxyethyl methacrylate)- $b$ polydimethylsiloxane- $b$-poly (2-hydroxyethyl methacrylate) (pHEMA$b$-PDMS-b-pHEMA) amphiphilic triblock copolymers were synthesized from three different PDMS macroinitiators with varying molecular weights by ATRP. The effect of hydrophilic (pHEMA) and hydrophobic (PDMS) content on the bulk physical properties of the triblock copolymers was studied via dynamic mechanical analysis (DMA). The influence of the block length of the triblock copolymers on the particle size and particle size distribution of micelles was examined using dynamic light scattering (DLS). The film morphology and nano-structure was studied by atomic force microscopy (AFM) and small angle X-ray scattering (SAXS). Transmission electron microscopy (TEM) was used to analyze the micelle morphologies.

\section{EXPERIMENTAL PROCEDURE}

\section{Materials}

Carbinol-terminated PDMS, DMS-C15 (number-average molecular weight $\left.\left(M_{\mathrm{n}}\right), \sim 1400 \mathrm{~g} \mathrm{~mol}^{-1}\right)$, DMS-C21 $\left(M_{\mathrm{n}}, \sim 3700 \mathrm{~g} \mathrm{~mol}^{-1}\right)$ and DMS-C23 $\left(M_{\mathrm{n}}\right.$ $\sim 7800 \mathrm{~g} \mathrm{~mol}^{-1}$ ) were obtained from Gelest, Inc., Morrisville, PA, USA. HEMA was obtained from Aldrich (St Louis, MO, USA) and purified as previously reported. ${ }^{17}$ The HEMA was removed from the inhibitor and other impurities after passing the monomer through a neutral silica column. The monomers were eluted with a 30/70 benzene/ethyl acetate solvent mixture; next, the monomer and solvent mixture were subjected to vacuum distillation. Copper (I) chloride, 2-bromoisobutyryl bromide, bipyridine (bpy), methyl ethyl ketone and 1-propanol were purchased from Aldrich. Reagents were used as received.

\section{Synthesis of PDMS macroinitiator}

Samples of carbinol-terminated PDMS with three different molecular weights were modified with 2-bromoisobutyryl bromide to obtain the macroinitiator. For example, DMS-C15 $(9.97 \mathrm{~g}, 7.12 \mathrm{mmol})$ was dissolved in $300 \mathrm{ml}$ of dichloromethane, which was followed by the addition of triethylamine $(4.34 \mathrm{~g}, 42.9 \mathrm{mmol})$ in a one-neck flask. The flask was placed into an icebath and cooled to $0{ }^{\circ} \mathrm{C}$. 2-Bromoisobutyryl bromide $(9.86 \mathrm{~g}, 42.9 \mathrm{mmol})$ was added dropwise into the flask through a dropping funnel under an inert atmosphere. The mixture was stirred for $16 \mathrm{~h}$, after which the reaction was stopped. Dichloromethane was removed in vacuo, and excess methanol was added to remove triethylamine bromide salt (the esterification by-product of carbinol-terminated polydimethyl siloxane and 2-bromoisobutyryl bromide). The extraction of salt with methanol was repeated three times. The methanol remaining in the final product was removed in vacuo at room temperature and used as the macroinitiator for the HEMA polymerization. The conversion yield of carbinol-terminated PDMS to the PDMS macroinitiator was almost 99 $\mathrm{wt} \%$. The chemical structure of the macroinitiator was confirmed by nuclear magnetic resonance (NMR) analysis: ${ }^{1} \mathrm{H}-\mathrm{NMR}\left(\mathrm{CDCl}_{3}\right): \delta 0.15\left(\mathrm{Si}-\mathrm{CH}_{3}\right), 1.29$ $\left(\mathrm{Si}-\mathrm{C}(=\mathrm{O})-\mathrm{CH}_{2}-\mathrm{CH}_{2}-\mathrm{CH}_{3}-\right.$, carbinol $), 1.56\left(\mathrm{Si}-\mathrm{C}(=\mathrm{O})-\mathrm{CH}_{2}-\mathrm{CH}_{2}-\mathrm{CH}_{3}-\right.$, carbinol), $2.23\left(\mathrm{Si}-\mathrm{C}(=\mathrm{O})-\mathrm{CH}_{2}-\mathrm{CH}_{2}-\mathrm{CH}_{3}-\right.$, carbinol $), 2.02 \quad(-\mathrm{C}(=\mathrm{O})$ $\left(-\mathrm{CH}_{3}\right)_{2} \mathrm{Br}$, carbinol), $4.08\left(\mathrm{CH}_{3}-\mathrm{C}(=\mathrm{O})\left(-\mathrm{CH}_{3}\right)_{2} \mathrm{Br}\right.$, carbinol).

\section{Synthesis of pHEMA- $b$-PDMS- $b$-pHEMA (ABA) triblock copolymer}

A series of triblock copolymers was synthesized by ATRP. For example, H80S20 was synthesized according to following procedure. The macroinitiator with $3700 \mathrm{~g} \mathrm{~mol}^{-1}$ (1.85 g, $0.5 \mathrm{mmol}$ ) was charged with a solvent mixture of MEK/ 1-propanol $(10 \mathrm{~g}, 70 / 30 \mathrm{v} / \mathrm{v})$ into a $100 \mathrm{ml}$ flask. bpy $(0.156 \mathrm{~g}, 1 \mathrm{mmol})$ and the HEMA monomer $(9.65 \mathrm{~g}, 75 \mathrm{mmol})$ were added into the solution, and the mixture was purged with nitrogen gas for $15 \mathrm{~min}$. Copper (I) chloride $(0.0495 \mathrm{~g}, 0.5 \mathrm{mmol})$ was charged into the vessel, and the solution was purged with nitrogen for additional $10 \mathrm{~min}$. The mole ratio of the components was HEMA/macroinitiator/CuCl/bpy: 150/1/1/2. The flask was sealed with a rubber septum, and the reaction was performed at $60^{\circ} \mathrm{C}$ for $24 \mathrm{~h}$. The reaction was quenched by exposing the solution to air and diluting it with a solvent mixture of MEK/1-propanol $(70 / 30 \mathrm{v} / \mathrm{v})$. The mixture was eluted from a silica (200 mesh) column using the same solvent mixture to remove the catalyst. The solvents were removed in vacuo, and the polymer was then precipitated in $n$ hexane $(150 \mathrm{ml})$. The precipitation sequence was repeated three times to remove all of the unreacted HEMA monomer. The polymerization yield was determined as $93 \%$ by gravimetric methods. Conversion was also determined by NMR spectroscopy to study polymerization kinetics. The theoretical number-average molecular weight $\left(M_{\mathrm{n}}\right)$ of pHEMA was changed by varying mole ratio of HEMA/macroinitiator to synthesize series of triblock copolymers ${ }^{18}$ to afford the following: ${ }^{1} \mathrm{H}-\mathrm{NMR}\left(\mathrm{CDCl}_{3}, \mathrm{CD}_{3} \mathrm{OD}\right): \delta 0.15\left(\mathrm{Si}-\mathrm{CH}_{3}\right)$, $1.24 \quad\left(\mathrm{CH}_{2}-\mathrm{C}\left(-\mathrm{CH}_{3}\right)-\mathrm{C}(=\mathrm{O})-\mathrm{CO}\right), \quad 1.56 \quad\left(\mathrm{C}(=\mathrm{O})-\mathrm{CH}_{2}-\mathrm{CH}_{2}-\mathrm{CH}_{3}-\right.$, carbinol) $1.97\left(-\mathrm{CH}_{2}-\mathrm{C}\left(-\mathrm{CH}_{3}\right)-\right), 3.85\left(\mathrm{CH}_{2}-\mathrm{CH}_{2}-\mathrm{OH}\right), 4.13\left(\mathrm{CO}-\mathrm{CH}_{2}-\right.$ $\left.\mathrm{CH}_{2}-\mathrm{OH}\right), 4.91\left(\mathrm{CH}_{2}-\mathrm{CH}_{2}-\mathrm{OH}\right)$.

\section{Gel permeation chromatography (GPC)}

GPC analysis was performed after the triblock copolymers were modified with chlorotrimethylsilane through the HEMA hydroxyl moiety because of the lack of a common solvent in which both PDMS and pHEMA are soluble. Therefore, each triblock $(65 \mathrm{mg})$ copolymer was dissolved in tetrahydrofuran (THF) $(10 \mathrm{ml})$. Triethylamine $(0.118 \mathrm{~g}, 1.17 \mathrm{mmol})$ was added next. The flask was put in an ice-bath until the solution temperature reached $0^{\circ} \mathrm{C}$. Chlorotrimethylsilane $(0.127 \mathrm{~g}, 1.17 \mathrm{mmol})$ was added dropwise into the flask for $1 \mathrm{~h}$. The resulting mixture was stirred for $2 \mathrm{~h}$. THF was removed in vacuo. Salt by-products were removed by washing with deionized water. The trimethylsilane-modified triblock copolymer in the flask was dried under vacuum overnight.

The modified triblock copolymer was dissolved in THF for GPC analysis. The molecular weights and molecular weight distributions were measured according to polystyrene standards in high-resolution Water columns with a THF flow rate of $1 \mathrm{ml} \mathrm{min}^{-1}$. The GPC traces of the triblock copolymers were unimodal.

The number-average molecular weights obtained from GPC and NMR were compared with the theoretical values $\left(M_{\mathrm{n}, \mathrm{th}}\right)$ for each pHEMA block determined by following equation:

$$
M_{\mathrm{n}, \mathrm{th}}=\frac{\text { Amount of } \operatorname{HEMA}(\mathrm{g})}{\text { Macroinitiator }(\mathrm{mol}) \times 2}
$$

\section{NMR spectroscopy}

NMR of amphiphilic copolymers was taken in $d$-chloroform $\left(\mathrm{CDCl}_{3}\right)$ and/or $d$-methanol $\left(\mathrm{CD}_{3} \mathrm{OD}\right)$ solvent in Varian Mercury 300 . The determination of $M_{\mathrm{n}}$ was accomplished by dissolving the block copolymers in $\mathrm{CD}_{3} \mathrm{OD}$ for the copolymers with the smaller PDMS blocks (H97S3, H92S8 and H96S4). However, a solvent mixture of $\mathrm{CDCl}_{3}$ and $\mathrm{CD}_{3} \mathrm{OD}(1 / 1 \mathrm{w} / \mathrm{w})$ was used for the copolymers with higher amounts of PDMS (H67S33 and H56S44). The polymerization kinetics were also determined by NMR. Before the addition of the copper catalyst, an aliquot of the polymerization mixture was dissolved in $\mathrm{CDCl}_{3}$. NMR spectra were obtained for this first aliquot and for other aliquots sampled at varying times during ATRP. The number-average molecular weight $\left(M_{\mathrm{n}}\right)$ of pHEMA was calculated after the removal of unreacted HEMA by precipitation in cold methanol. The integration ratio of the resonances at $\delta$ $\sim 5-6$ p.p.m. (double bond, $\mathrm{HC}=$, from HEMA) and $\delta \sim 0$ p.p.m. $\left(-\mathrm{CH}_{3}\right.$ from PDMS) was determined during polymerization. This ratio decreased during polymerization. The monomer conversion was determined by comparing the integration ratios of these resonances before and during the reaction. The integration ratio of the peak resonances at $\delta \sim 4.2$ p.p.m. $\left(2 \mathrm{H},-\mathrm{COOCH}_{2}\right.$, from HEMA) to $\delta \sim 0$ p.p.m. ( $6 \mathrm{H},-\mathrm{CH}_{3}$ from PDMS) was determined. This ratio was multiplied by the $M_{\mathrm{n}}$ of PDMS (from GPC) to determine the $M_{\mathrm{n}}$ of 
pHEMA. The block copolymer molecular weight was determined by adding the PDMS and pHEMA $M_{\mathrm{n}}$ values.

\section{Dynamic mechanical analysis}

A Perkin Elmer Pyris Diamond was used for DMA. The block copolymer solution ( $5 \mathrm{wt} \%)$ was prepared in THF and cast on a glass substrate. The film was dried at room temperature overnight. A film $\left(50 \times 50 \mathrm{~mm}^{2}\right)$ was used for testing. DMA was performed in compression mode at a heating rate of $4{ }^{\circ} \mathrm{C} \mathrm{min}^{-1}$ under $40 \mathrm{psi}$ of nitrogen flow at a constant oscillating frequency of $1 \mathrm{~Hz}$.

\section{Transmission electron microscopy}

A Philips Tacnai-12 model with a high-resolution imaging scanning transmission electron microscope, a $120 \mathrm{kV}$ illumination system, maximum magnification of $500 \mathrm{~K}$, and maximum resolution of $<1 \mathrm{~nm}$ was operated. The block copolymers $(1 \mathrm{mg})$ were dissolved in solvents (methanol, methanol-water mixture and THF) to afford $0.1 \mathrm{wt} \%$ solutions. The polymers dissolved easily in methanol and THF. However, methanol-water was not a good solvent for the block copolymers. Therefore, water $(50 \mathrm{v} \%)$ was added to the polymer after it was dissolved in methanol (50 v\%). The polymer solution was dropped onto copper TEM grids. Samples were stained with $1 \mathrm{wt} \%$ aqueous sodium phosphotungstate and dried at room temperature.

\section{Dynamic light scattering}

A Brookhaven Instruments BI-200SM system equipped with a He-Ne laser operated at $632.8 \mathrm{~nm}$ with a $1 \mathrm{~mm}$ entrance aperture was used to analyze the particle size and particle size distribution. The triblock copolymers (0.2 and 0.1 $\mathrm{wt} \%$ ) were dissolved in THF and methanol. All solutions were passed through a Teflon membrane filter with a $0.45 \mu \mathrm{m}$ pore size before analysis. Scattering measurements were performed at $25^{\circ} \mathrm{C}$ and a $90^{\circ}$ angle.

\section{Small angle $\mathrm{X}$-ray scattering}

Amphiphilic triblock copolymers $(0.5 \mathrm{~g})$ were dissolved in MEK/propanol $(0.5 \mathrm{~g}, 70 / 30 \mathrm{v} / \mathrm{v})$. This solution was cast to a glass substrate. Films were dried at room temperature for 3 days. A small piece of film $\left(1 \times 1 \mathrm{~mm}^{2}\right)$ was analyzed in a Rigaku micromax-002t high-intensity microfocus sealed X-ray generator SAXS instrument with a Rigaku multiwire position-sensitive X-ray and Varian $\mathrm{Cu} X$-ray tube. The instrument was operated at $45 \mathrm{kV} \times 0.88 \mathrm{~mA}$ power, which produced X-rays for $10 \mathrm{~min}$ at room temperature. The twodimensional X-ray pattern was integrated through the azimuthal angle and calibrated using a Ag-behenate crystal to yield the scattering intensity as a function of the scattering vector $(q)$. One of the copolymers (H80S20) was heated by $4{ }^{\circ} \mathrm{C}$ per min during the SAXS measurements to observe the effect of temperature on the structure order at $25,50,75$ and $100^{\circ} \mathrm{C}$.

\section{Atomic force microscopy}

AFM images were taken using a Veeco (Digital Instruments) Multimode instrument with a $10 \mu \mathrm{ms}^{-1}$ scan rate and under ambient conditions. The block copolymers were dissolved in THF to prepare a $0.2 \mathrm{wt} \%$ polymer solution, which was spin-cast on a glass substrate at 3000 r.p.m. for $15 \mathrm{~s}$.

\section{RESULTS}

Amphiphilic polymers are composed of hydrophilic and hydrophobic segments. These copolymers can undergo self-assembly in solution or melt state due to the blocks being incompatible. The amphiphilic structure leads to micellar formation through the self-assembly of insoluble segments in a selective solvent. The presence of micelles leads to different flow and structural characteristics than those of a homopolymer of any single block.

In previous studies, several different amphiphilic block copolymers were synthesized, such as PEO- $b$-PS- $b$-PAA, ${ }^{19}$ (PAA- $b$-PS) 6 (star PAA$b$-PS $),{ }^{20}$ P(DMS- $b$-MMA- $b$-DMAEMA $),{ }^{21} \quad$ P(Sty-DMS- $b$-MMA ${ }^{22}$ and PEA- $b$-PEO- $b$-PEA. ${ }^{23}$ Previously, pHEMA- $b$-PDMS- $b$-pHEMA triblock copolymers with varying block molecular weights had not been polymerized by ATRP. Additionally, the effects of pHEMA or PDMS block length on physical properties such as particle size, mechanical properties and film morphology are still unknown. Studying pHEMA- $b$-PDMS- $b$-pHEMA triblock copolymers is crucial in several aspects such as amphiphilicity, possessing hardsoft segments and hybrid backbone having organic (pHEMA) and inorganic (PDMS) polymer blocks. The solubility parameters of pHEMA and PDMS differ significantly, which might lead to nanoscale phase separation and self-assembly.

\section{Synthesis of pHEMA- $b$-PDMS- $b$-pHEMA (ABA) triblock copolymer}

Scheme 1 shows the synthesis of triblock copolymers with PDMS (middle block) and pHEMA. 2, 2'-bpy was used as a ligand for the $\mathrm{CuCl}$ catalyst. These components were mixed with the PDMS macroinitiator and HEMA in a solvent mixture of methyl ethyl ketone and 1-propanol. The reaction was performed in an oil bath for $24 \mathrm{~h}$ at $60^{\circ} \mathrm{C}$.

\section{Gel permeation chromatography}

Table 1 shows the molecular weights and molecular weight distributions of the pHEMA- $b$-PDMS- $b$-pHEMA triblock copolymer series.

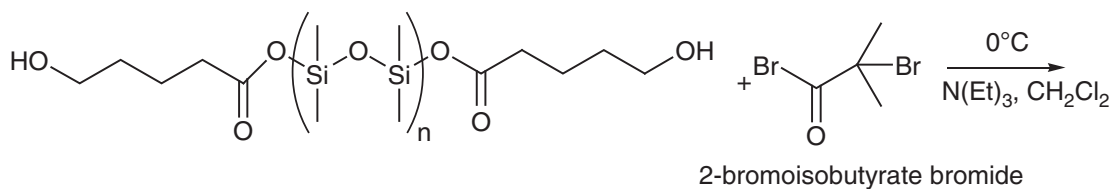

Carbinol terminated Silanol

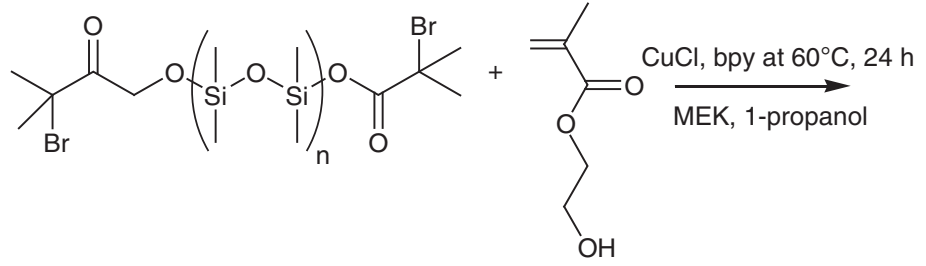

$(\mathrm{HEMA})_{\mathrm{m}}$-PDMS-(HEMA $)_{m}$

2-Hydroxyethyl Methacrylate

Scheme 1 Synthesis conditions of macroinitiator and amphiphilic triblocks. 
Table 1 Molecular weight and molecular weight distribution of a series of block copolymers synthesized by ATRP

\begin{tabular}{|c|c|c|c|c|c|c|c|}
\hline & $\begin{array}{c}\text { Theoretical } \\
\mathrm{M}_{n}\end{array}$ & $\begin{array}{l}\mathrm{M}_{n} \text { of } \\
\text { PDMS }\end{array}$ & $\begin{array}{l}\text { PDI of } \\
\text { PDMS }\end{array}$ & $\begin{array}{c}\text { pHEMA/ } \\
\text { PDMS }\end{array}$ & $\begin{array}{c}\mathrm{M}_{n} \\
(G P C)\end{array}$ & $\begin{array}{c}\mathrm{M}_{n} \\
(N M R)\end{array}$ & $\begin{array}{l}\mathrm{M}_{\mathrm{w}} \\
\mathrm{M}_{n}\end{array}$ \\
\hline H80S20a & $\begin{array}{c}10 \mathrm{~K}-3.7 \mathrm{~K}- \\
10 \mathrm{~K}\end{array}$ & 3700 & 1.92 & $80.0 / 20.0$ & 19300 & 19700 & 1.5 \\
\hline H67S33 & $\begin{array}{c}5 \mathrm{~K}-3.7 \mathrm{~K}- \\
5 \mathrm{~K}\end{array}$ & 3700 & 1.92 & $66.7 / 33.3$ & 13400 & 9300 & 1.3 \\
\hline H86S14 & $\begin{array}{c}15 \mathrm{~K}-3.7 \mathrm{~K}- \\
15 \mathrm{~K}\end{array}$ & 3700 & 1.92 & $85.6 / 14.4$ & 35100 & 28900 & 1.5 \\
\hline H71S29 & $\begin{array}{c}10 \mathrm{~K}-7.8 \mathrm{~K}- \\
10 \mathrm{~K}\end{array}$ & 7800 & 2.03 & $71.4 / 28.6$ & 27500 & 25300 & 1.5 \\
\hline H56S44 & $\begin{array}{c}5 \mathrm{~K}-7.8 \mathrm{~K}- \\
5 \mathrm{~K}\end{array}$ & 7800 & 2.03 & $55.6 / 44.4$ & 21400 & 16400 & 1.5 \\
\hline H79S21 & $\begin{array}{c}15 \mathrm{~K}-7.8 \mathrm{~K}- \\
15 \mathrm{~K}\end{array}$ & 7800 & 2.03 & 78.9/21.1 & 41600 & 34600 & 1.5 \\
\hline H97S3 & $\begin{array}{c}15 \mathrm{~K}-1.4 \mathrm{~K}- \\
15 \mathrm{~K}\end{array}$ & 1400 & 1.25 & $97.2 / 2.8$ & 34300 & 22500 & 1.4 \\
\hline H92S8 & $\begin{array}{c}5 \mathrm{~K}-1.4 \mathrm{~K}- \\
5 \mathrm{~K}\end{array}$ & 1400 & 1.25 & $91.7 / 8.3$ & 21200 & 12500 & 1.5 \\
\hline H96S4 & $\begin{array}{c}10 \mathrm{~K}-1.4 \mathrm{~K}- \\
10 \mathrm{~K}\end{array}$ & 1400 & 1.25 & $95.7 / 4.3$ & 31600 & 20500 & 1.2 \\
\hline
\end{tabular}

Abbreviations: GPC, gel permeation chromatography; $M_{\mathrm{W}}$, weight-average molecular weight; NMR, nuclear magnetic resonance.

a Nomenclature is as follows: H: pHEMA, 80: wt\% of pHEMA in the triblock copolymer, S: PDMS, 20: wt \% of PDMS in the triblock copolymer.

The polymerizations were performed in a mixture of methyl ethyl ketone and propanol $(70 / 30 \mathrm{w} / \mathrm{w})$ using PDMS as the macroinitiator. The choice of this solvent mixture ensures the solubility of the pHEMA and PDMS polymers and hence the pHEMA- $b$-PDMS- $b$ pHEMA copolymers. The NMR experiments (H97S3, H92S8, H96S4) were performed by dissolving the block copolymers in $d$-methanol $\left(\mathrm{CD}_{3} \mathrm{OD}\right)$, in which both PDMS $\left(M_{\mathrm{n}}, 1400 \mathrm{~g} \mathrm{~mol}^{-1}\right)$ and pHEMA are highly soluble, whereas a mixture of $\mathrm{CDCl}_{3}$ and $\mathrm{CD}_{3} \mathrm{OD}(1 / 1 \mathrm{w} / \mathrm{w})$ was used to dissolve H67S33 and H56S44 because PDMS with a $M_{n}$ above $3000 \mathrm{~g} \mathrm{~mol}^{-1}$ is not soluble in $\mathrm{CD}_{3} \mathrm{OD}$ alone.

The GPC- and NMR-derived $M_{\mathrm{n}}$ values differed significantly. This difference increased as the theoretical $M_{\mathrm{n}}$ of pHEMA block increased. This trend could be attributed to the larger hydrodynamic volume of amphiphilic copolymers with higher amount of HEMA compared with the linear PS standard used in the GPC column. The larger hydrodynamic volume of amphiphilic copolymers could be due to the formation of larger micelles during GPC analysis.

The PDI of macroinitiators decreased dramatically after polymerization with the exception of the PDI of macroinitiator $\left(1400 \mathrm{~g} \mathrm{~mol}^{-1}\right)$. The increase in the PDI of macroinitiator $\left(1400 \mathrm{~g} \mathrm{~mol}^{-1}\right)$ could be due to the polymerization, which did not proceed with a living mechanism. ${ }^{24,25}$ This behavior could be caused by a loss of active radicalic species, especially at the beginning of the polymerization. This statement was supported by the slower polymerization kinetics when macroinitiator $\left(1400 \mathrm{~g} \mathrm{~mol}^{-1}\right)$ was used (see Figure 2).

\section{NMR analysis}

All block copolymers are dispersible in either organic or mixture of aqueous-organic solvent medium. In methanol or methanol-water, block copolymers with PDMS $\left(M_{\mathrm{n}}>3000 \mathrm{~g} \mathrm{~mol}^{-1}\right)$ form micelles with a PDMS core and pHEMA shell. The micelle formation was confirmed by NMR spectroscopy. Figures $1 \mathrm{a}$ and $\mathrm{b}$ show the NMR spectra of pHEMA- $b$-PDMS- $b$-pHEMA (H67S33) in a non-selective $\left(\mathrm{CDCl}_{3}\right.$ and $\mathrm{CD}_{3} \mathrm{OD}$ mixture, $\left.1 / 1 \mathrm{w} / \mathrm{w}\right)$ and a selective ( $d$-methanol) solvent, respectively. The ratio of the integrated peak areas from the $-\mathrm{CH}_{3}$ moiety of PDMS to the $-\mathrm{OCH}_{2}$ moiety of HEMA was used to confirm the micelle formation in a selective solvent. The integration ratio $\left(-\mathrm{CH}_{3} /-\mathrm{OCH}_{2}\right)$ decreased from 0.8 to 0.15 when the solvent mixture $\left(\mathrm{CDCl}_{3}\right.$ and $\left.\mathrm{CD}_{3} \mathrm{OD}, 1 / 1 \mathrm{w} / \mathrm{w}\right)$ was changed to neat methanol. The decrease in the integration ratio $\left(-\mathrm{CH}_{3} /-\mathrm{OCH}_{2}\right)$ suggested the aggregation of PDMS segments in methanol, forming core-shell aggregations (micelles) from reverse micelles in the solvent mixture of $\mathrm{CDCl}_{3}$ and $\mathrm{CD}_{3} \mathrm{OD}$. The formation of core-shell aggregates could be attributed to the superior solubility of pHEMA blocks in methanol whereas PDMS blocks minimized the interaction with methanol. In a polar solvent such as $\mathrm{CD}_{3} \mathrm{OD}$, PDMS blocks form a dense hydrophobic core surrounded by polar pHEMA blocks. This arrangement minimizes the free energy of pHEMA. Figure 1c shows the NMR spectra of the block copolymer in $\mathrm{CDCl}_{3}$ and $\mathrm{CD}_{3} \mathrm{OD}, 4 / 1 \mathrm{w} / \mathrm{w}$. In this solvent mixture, the integration ratio $\left(-\mathrm{CH}_{3} /-\mathrm{OCH}_{2}\right)$ increased from 0.8 to 0.9 , suggesting the formation of reverse micelles with a pHEMA core and PDMS shell. In this case, the hydrophilic blocks, pHEMA, formed a core through H-bonding. The formation of micelles or reverse micelles depending upon the solvent could be explained by the surfactant behavior of the amphiphilic copolymer.

\section{Kinetics}

NMR spectroscopy was used to determine the percent conversion of HEMA as a function of time. The overall conversion of HEMA reached almost $80 \%$ within $1 \mathrm{~h}$. The polymerization kinetics of the amphiphilic triblock copolymers with three different macroinitiators $\left(M_{\mathrm{n}}, 1400,3700,7800 \mathrm{~g} \mathrm{~mol}^{-1}\right)$ was performed. In each case, the pHEMA blocks with the theoretical number-average molecular weight $\left(M_{\mathrm{n}}, \sim 10000 \mathrm{~g} \mathrm{~mol}^{-1}\right)$ were grown on three different macroinitiators. Figure 2 shows the polymerization kinetics of pHEMA- $b$-PDMS- $b$-pHEMA. Linear reaction kinetics was observed, implying first-order ATRP kinetics and a constant number of growing species during polymerization. ${ }^{26}$ The macroinitiator with the highest molecular weight $\left(M_{\mathrm{n}}, 7800 \mathrm{~g} \mathrm{~mol}^{-1}\right)$ exhibited the most rapid polymerization; the other two macroinitiators had almost identical reaction rates. All of the reaction plots indicated controlled polymerization. Figure 3 shows $M_{\mathrm{n}}$ and the PDI as a function of conversion \% for three different macroinitiators. The $M_{\mathrm{n}}$ of amphiphilic triblock copolymers increased linearly with conversion (\%). The PDIs of macroinitiators (3700 and $7800 \mathrm{~g} \mathrm{~mol}^{-1}$ ) decreased from $\sim 2$ to $\sim 1.5$ as the conversion increased. These macroinitiators enabled controlled polymerizations. However, the PDI of macroinitiator $\left(1400 \mathrm{~g} \mathrm{~mol}^{-1}\right)$ increased from 1.2 to 1.5. A significant increase in PDI was observed, especially at the beginning of polymerization, most likely due to slow or uninitiated polymerization.

\section{DLS study}

Micellar and reverse micellar sizes of triblock copolymers were obtained from DLS studies. Table 2 summarizes the DLS results of triblock copolymer assemblies in THF, methanol and a methanolwater mixture. The block copolymer samples with less PDMS, that is, H97S3, H92S8 and H96S4, yielded smaller micelles and micellar aggregates than H80S20, H67S33 and H86S14 in methanol due to their low ratio of hydrophobic/hydrophilic content. The particle size 
a

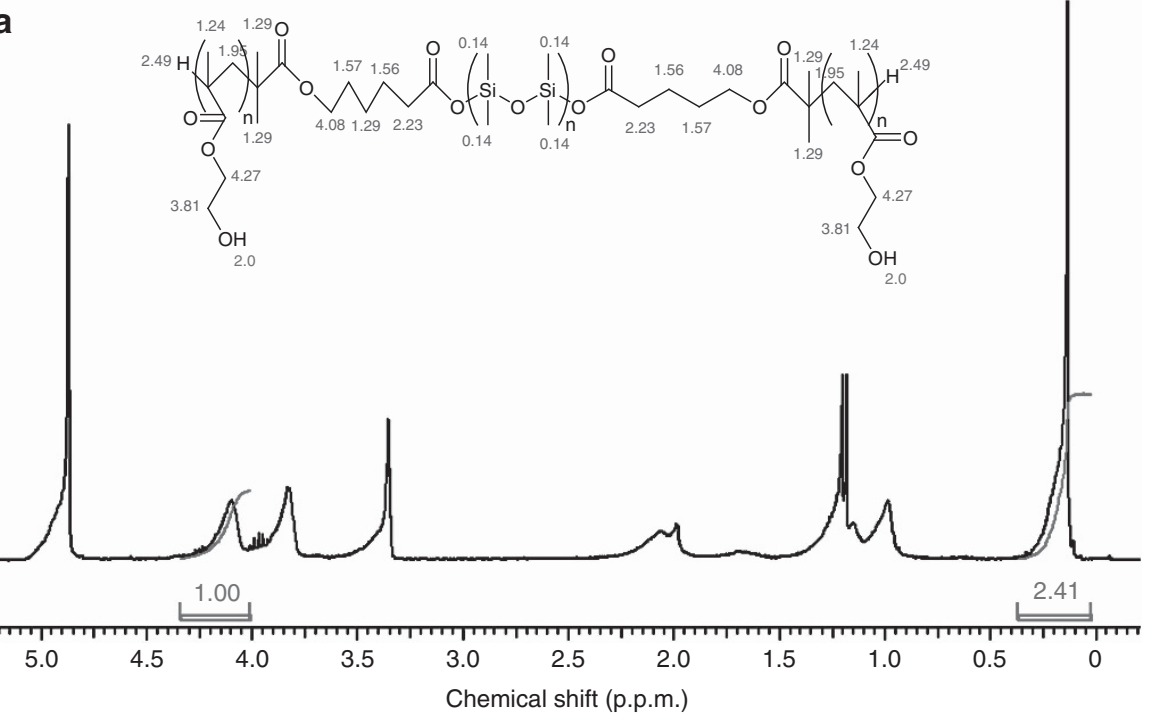

b

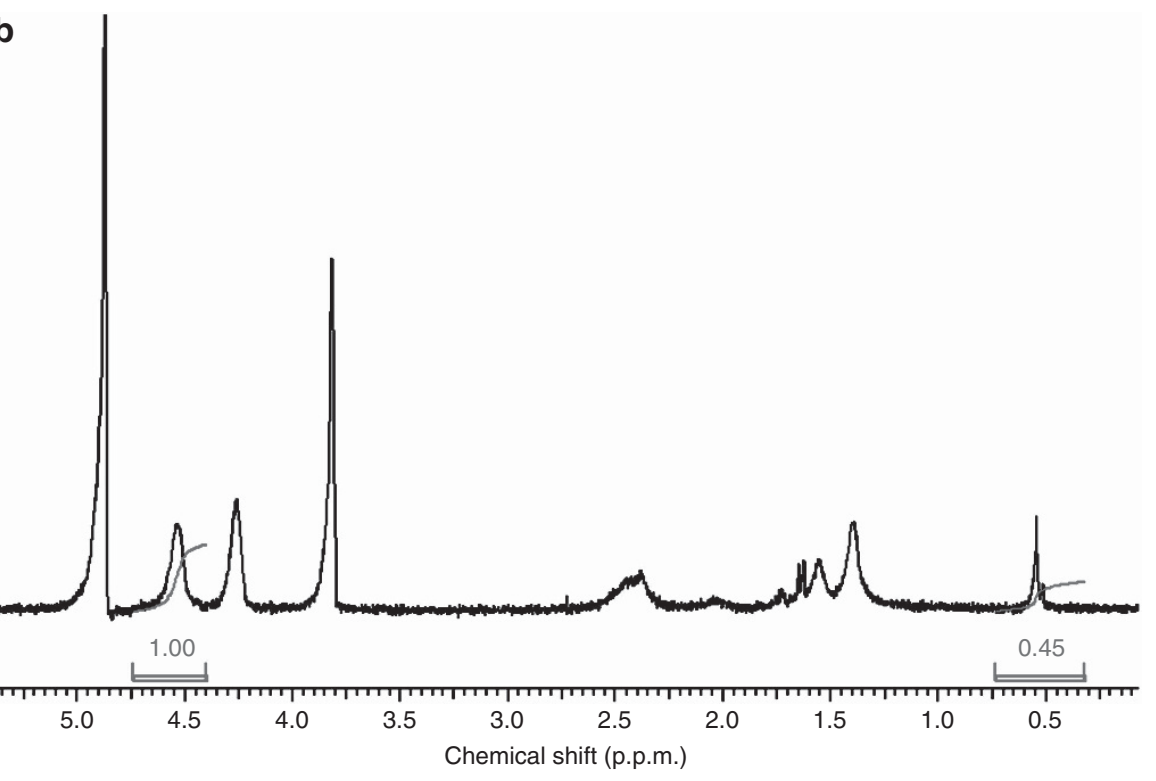

C

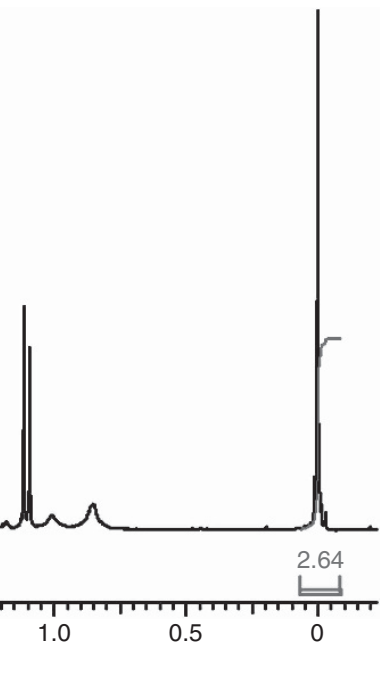

Figure 1 NMR spectra of H67S33 in (a) 1/1: methanol/chloroform, (b) excess methanol and (c) excess chloroform. A full color version of this figure is available at Polymer Journal online. 
of triblock copolymers (H80S20, H67S33, H86S14) increases as the length of the hydrophilic block increases for a fixed hydrophobic block length $\left(3700 \mathrm{~g} \mathrm{~mol}^{-1}\right)$. Similarly, the micellar diameter increased as a function of PDMS content for a fixed pHEMA block

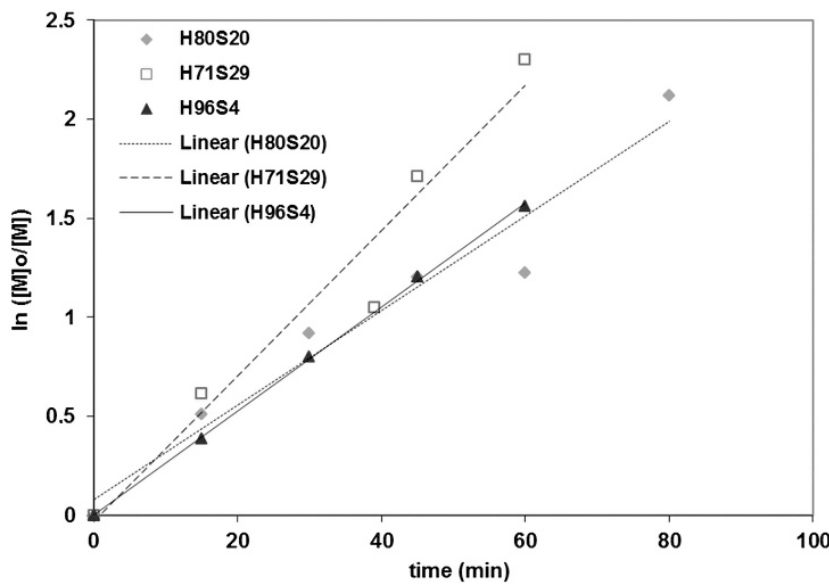

Figure 2 ATRP kinetics of pHEMA- $b$-PDMS- $b$-pHEMA triblock copolymers for three different macroinitiators with $M_{\mathrm{n}}, 1400,3700$ and $7800 \mathrm{~g} \mathrm{~mol}^{-1}$. A full color version of this figure is available at Polymer Journal online. length $\left(5000 \mathrm{~g} \mathrm{~mol}^{-1}\right)$. The same trend was observed for the reverse micelles in THF.

In amphiphilic copolymers, the CMC decreases as the ratio of hydrophobic/hydrophilic content increases, resulting in larger

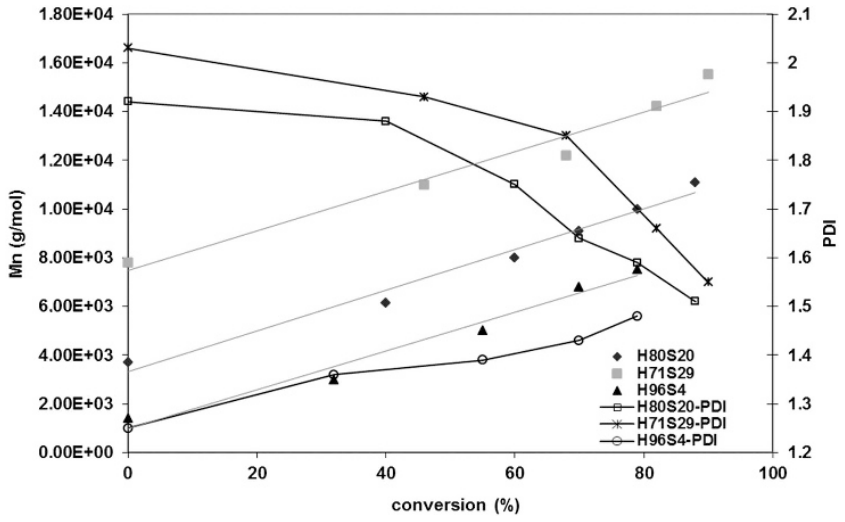

Figure 3 Number-average molecular weight $\left(M_{n}\right)$ and PDI for three different macroinitiators with $M_{\mathrm{n}}, 1400,3700$ and $7800 \mathrm{~g} \mathrm{~mol}^{-1}$ as a function of conversion \%. A full color version of this figure is available at Polymer Journal online.

Table 2 Particle sizes (mean diameters shown) in methanol, THF and methanol/water mixture obtained by DLS

\begin{tabular}{|c|c|c|c|c|c|c|c|}
\hline Sample name & $\begin{array}{c}\text { Molecular } \\
\text { weight }\end{array}$ & $P S D$ in $T H F(n m)$ & THF (nm) & PSD in methanol (nm) & $\begin{array}{c}\text { Methanol } \\
(n m)\end{array}$ & $P S D$ in methanol/water (95/5) (nm) & Methanol/water (95/5) (nm) \\
\hline H8OS2O & $10 \mathrm{~K}-3.7 \mathrm{~K}-10 \mathrm{~K}$ & $\begin{array}{r}1.3 \pm 0.1 \\
17.8 \pm 0.3 \\
85.7 \pm 0.8\end{array}$ & $29.8 \pm 2.0$ & $\begin{array}{r}1.3 \pm 0.4 \\
17.8 \pm 0.6 \\
316.2 \pm 1.2\end{array}$ & $38.4 \pm 2.8$ & $\begin{array}{r}1.2 \pm 0.1 \\
45.9 \pm 0.7\end{array}$ & $44.9 \pm 5.3$ \\
\hline H67S33 & $5 K-3.7 K-5 K$ & $\begin{array}{r}1.2 \pm 0.2 \\
26.7 \pm 0.7 \\
183.8 \pm 1.5\end{array}$ & $14.3 \pm 6.3$ & $\begin{array}{r}1.3 \pm 0.3 \\
17.8 \pm 0.9 \\
421.7 \pm 1.8\end{array}$ & $26.1 \pm 3.1$ & $\begin{array}{r}1.3 \pm 0.2 \\
54.8 \pm 2.5\end{array}$ & $36.3 \pm 3.8$ \\
\hline H71S29 & $10 \mathrm{~K}-7.8 \mathrm{~K}-10 \mathrm{~K}$ & $\begin{array}{r}48.1 \pm 0.6 \\
368.1 \pm 1.5\end{array}$ & $33.7 \pm 5.9$ & $\begin{array}{r}1.1 \pm 0.1 \\
25.7 \pm 1.8\end{array}$ & $53.6 \pm 2.6$ & $\begin{array}{c}54.2 \pm 0.2 \\
157.6 \pm 0.15\end{array}$ & $74.8 \pm 4.0$ \\
\hline H56S44 & $5 K-7.8 K-5 K$ & $\begin{array}{r}1.2 \pm 0.2 \\
13.2 \pm 1.1 \\
133.3 \pm 1.6\end{array}$ & $20.7 \pm 5.8$ & $\begin{array}{r}1.6 \pm 0.2 \\
44.2 \pm 1.6\end{array}$ & $40.2 \pm 3.9$ & $\begin{array}{l}29.7 \pm 1.5 \\
82.8 \pm 3.5\end{array}$ & $59.3 \pm 5.7$ \\
\hline H97S3 & $15 \mathrm{~K}-1.4 \mathrm{~K}-15 \mathrm{~K}$ & $\begin{array}{r}1.2 \pm 0.2 \\
83.3 \pm 1.8 \\
227.8 \pm 2.1\end{array}$ & $22.6 \pm 4.4$ & $\begin{array}{r}1.3 \pm 0.3 \\
13.3 \pm 1.5 \\
133.3 \pm 2.4\end{array}$ & $33.6 \pm 2.8$ & $\begin{array}{r}1.2 \pm 0.5 \\
9.8 \pm 0.7 \\
36.0 \pm 0.8 \\
241.5 \pm 0.2\end{array}$ & $39.0 \pm 2.8$ \\
\hline H92S8 & $5 \mathrm{~K}-1.4 \mathrm{~K}-5 \mathrm{~K}$ & $\begin{array}{r}1.42 \pm 0.2 \\
134.1 \pm 1.4\end{array}$ & $10.4 \pm 5.6$ & $\begin{array}{r}1.3 \pm 0.2 \\
13.3 \pm 1.3 \\
316.2 \pm 3.3\end{array}$ & $15.6 \pm 2.7$ & $\begin{array}{r}1.2 \pm 0.6 \\
16.9 \pm 0.4 \\
143.1 \pm 2.3\end{array}$ & $24.1 \pm 4.8$ \\
\hline H96S4 & $10 \mathrm{~K}-1.4 \mathrm{~K}-10 \mathrm{~K}$ & $\begin{array}{r}1.3 \pm 0.1 \\
237.1 \pm 1.3\end{array}$ & $31.4 \pm 5.6$ & $\begin{array}{r}1.2 \pm 0.2 \\
17.6 \pm 1.9 \\
204.7 \pm 2.2\end{array}$ & $45.4 \pm 9.2$ & $\begin{array}{r}14.6 \pm 1.4 \\
178.7 \pm 1.5\end{array}$ & $60.2 \pm 5.1$ \\
\hline
\end{tabular}

Abbreviations: DLS, dynamic light scattering; PSD, particle size distribution. 
micelles. ${ }^{27}$ As the PDMS content increased, the micellar size of the triblock copolymers also increased. The triblock copolymers began to form larger micelles as the medium polarity increased with the addition of water into the methanol. The micellar diameter of H86S14 increased from $56 \mathrm{~nm}$ (in methanol) to $67.2 \mathrm{~nm}$ (in methanol-water) after the addition of water.

The use of THF led to fewer aggregations than the use of the methanol and methanol-water solvents. This dearth of aggregations resulted in lower DLS counts. Therefore, a high concentration of the triblock copolymer was needed when THF was used as solvent, almost as twice that needed when methanol was used. The aggregation of amphiphilic copolymers in THF was hindered by the back-folding and looping of the PDMS blocks, which increases the free energy of the system. ${ }^{28}$ This increase most likely resulted in the CMC of pHEMA- $b$-PDMS- $b$-pHEMA copolymers in THF being higher than that in methanol. As CMC increases micellar size decreases. Micellar size of most of the triblock copolymers in THF was smaller than that in methanol.

On the basis of the DLS results, a model for assemblies was suggested. Scheme 2 shows this model for assemblies of micelles and reverse micelles. In this model, many of the PDMS blocks aggregated in the core, whereas some of the hydrophilic pHEMA blocks were soluble and thus formed shells in methanol. The addition of water to methanol, that is, an increase in the solvent polarity, created larger micelles, especially in triblock copolymers with higher PDMS contents. pHEMA is not soluble in THF; therefore, the pHEMA blocks aggregated and formed the cores of the reverse micelles.

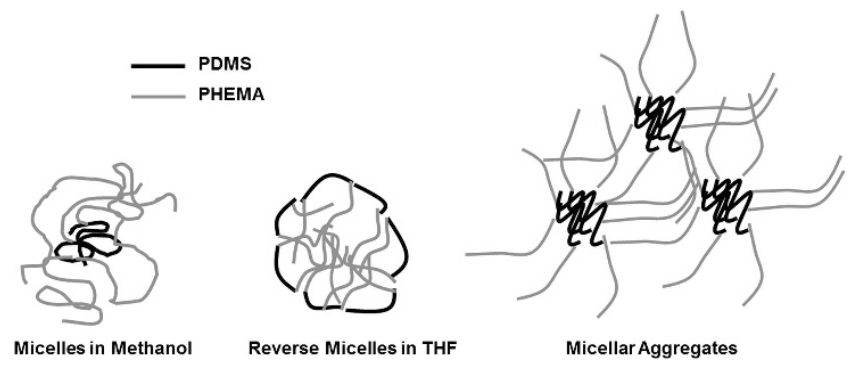

Scheme 2 Possible assemblies formed in organic solvents.

\section{TEM analysis}

TEM was used to study micellar behavior in different solvents. The polymer solutions were cast on copper grids and dried at room temperature. The average diameters of the micelles and reverse micelles were calculated. Figures $4 \mathrm{a}$ and $\mathrm{b}$ show the TEM images of micelles formed in methanol and in methanol-water. Figure 4c shows the TEM images of reverse micelles formed in THF. The polydisperse nature of particles is also shown in the TEM images, which supported the DLS analysis results. The high polydispersity in the particle diameters is attributed to the molecular weight polydispersity of the PDMS block in the copolymers. The most uniform particles were obtained from the methanol-water mixture; micellar clusters were obtained in methanol. Smaller micellar clusters were observed in THF owing to the back-folding of the triblock copolymers. Smaller particles were observed by TEM than by DLS. This difference could be attributed to shrinkage of the micelle coronas after casting the polymer solution on the TEM grid compared with the fully stretched state of the polymer chains in solvent.

\section{Small angle X-ray scattering}

SAXS was used to study the microdomain structure, lattice type and spacing between blocks based on the electron density differences between species. Ordered structures were obtained due to the relatively narrow PDIs of the polymers, especially when the lengths of the pHEMA and PDMS blocks were comparable. Figure 5 shows the SAXS profiles of triblock copolymers. Copolymers H80S20, H67S33, H86S14 and H71S29 showed reflections at $q$ value ratios of 1:2:3, indicating the presence of lamellae. The distance between repeating morphologies $(d)$ was higher in H71S29 due to the longer PDMS blocks. H56S44 and H79S21 exhibited randomly ordered structures with microphase separation, which was indicated by a very broad primary reflection. This structure was most likely due to the high $\mathrm{PDI}^{29}$ of the macroinitiator $\left(M_{\mathrm{n}}, 3700 \mathrm{~g} \mathrm{~mol}^{-1}\right.$, PDI, 2.1), which caused the sluggish diffusion of polymer chains and formed a sharp interface between soft and hard segment segregates. ${ }^{30}$ In these copolymers, chains were stacked in a metastable transient state that formed disordered spheres. As the pHEMA content increased to over $90 \mathrm{wt} \%$, such as in H97S3, H92S8 and H96S4, the ordered structure was disrupted due to the asymmetry between the pHEMA and PDMS blocks. These triblocks showed a high-intensity primary reflection followed by a weak, broad shoulder at higher $q$. This behavior indicated formation of liquid-like structure due to the kinetic limitations of the diffusivity of long pHEMA blocks with abundant H-bonds. ${ }^{31}$ Table 3 summarizes the SAXS results for each triblock
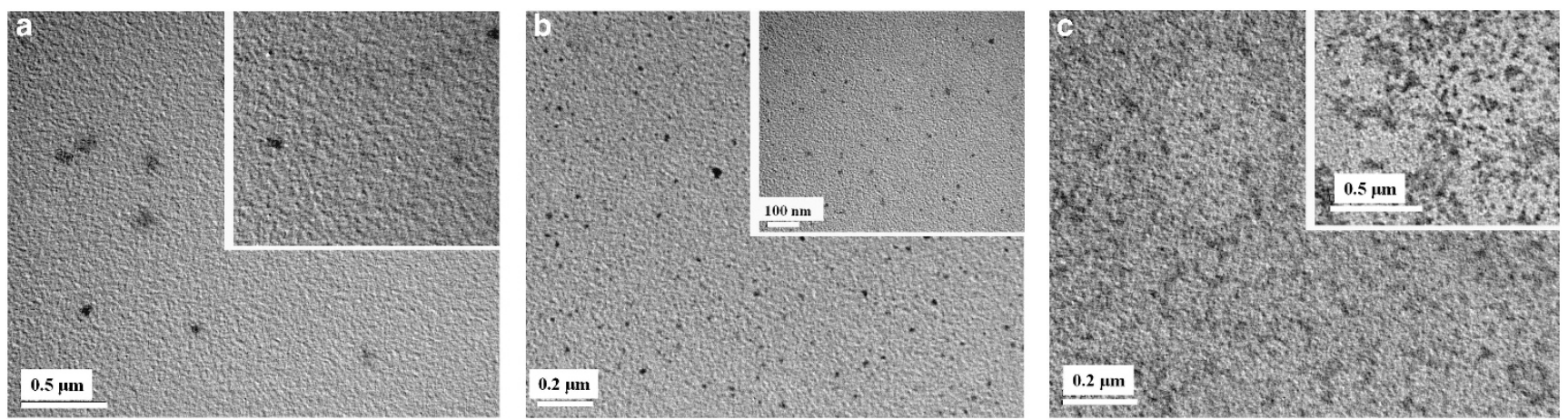

Figure 4 TEM image of H8OS20 in (a) methanol, (b) methanol-water (50/50 v/v) and (c) THF. 


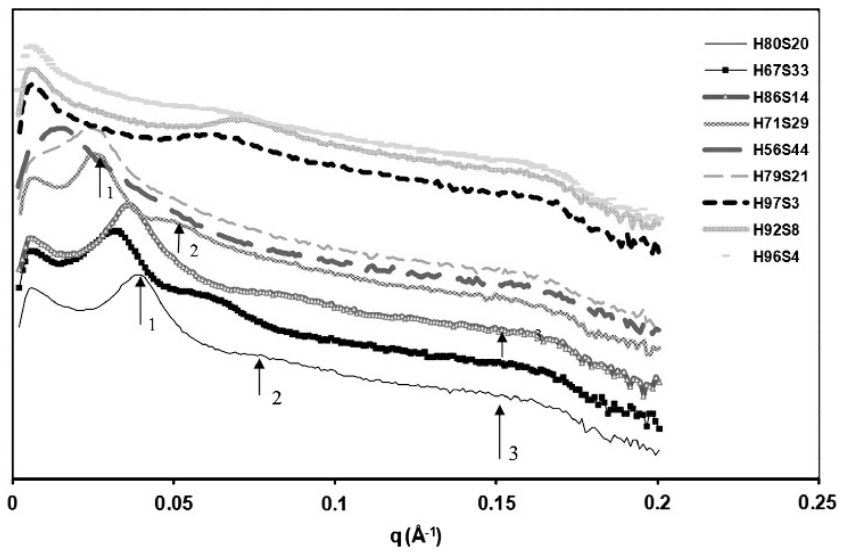

Figure 5 SAXS intensity profiles of samples as function of wave vector $q$. A full color version of this figure is available at Polymer Journal online.

Table $3 d$-Spacings of repeating morphology in triblock copolymers

\begin{tabular}{lccc}
\hline & $\begin{array}{c}\text { Primary reflection, } d \\
(\mathrm{~nm})\end{array}$ & $\begin{array}{c}\text { Secondary reflection } \\
(\mathrm{nm})\end{array}$ & $\begin{array}{c}\text { Intensity of primary } \\
\text { reflection }\end{array}$ \\
\hline H80S20 & 15.7 & 7.8 & 2.29 \\
H67S33 & 18.5 & 9.9 & 4.87 \\
H86S14 & 17.0 & 1.7 & 2.81 \\
H71S29 & 25.1 & 11.9 & 8.67 \\
H56S44 & 41.6 & 11.8 & 9.92 \\
H79S21 & 25.1 & 3.83 & 6.20 \\
H97S3 & 10.1 & 3.76 & 0.90 \\
H92S8 & 8.7 & 3.76 & 0.73 \\
H96S4 & 9.0 & 3.83 & 1.78 \\
\hline
\end{tabular}

copolymer. When the blocks are more miscible in one another, the intensity of reflections decreases. Higher PDMS content, which has high electron density, increased the X-ray contrast and, therefore, the intensity of the primary reflection. ${ }^{32}$ However, the intensity of the primary reflection decreased at very high pHEMA contents, most likely because of the superior miscibility of shorter PDMS blocks in pHEMA domains.

Figure 6 shows the effects of temperature on the SAXS profile of H80S20. As the temperature increased, the primary $d$-spacing increased from 15.3 to $16.5 \mathrm{~nm}$. The primary reflection became broader and the lamellar structures were destroyed at higher temperatures. The weak shoulder at $q=0.17 \AA^{-1}$ was attributed to a form factor due to interference between spherical micelles.

\section{Dynamic mechanical analysis}

The viscoelastic properties of the triblock copolymers were investigated by DMA analysis. The most important parameters in specifying the viscoelastic properties are block length $(N)$, block incompatibility $(\chi)$ and composition. The pHEMA and PDMS blocks are incompatible due to the very large difference in their solubility parameters, ${ }^{33}$ 26.9 and $14.9(\mathrm{MPa})^{1 / 2}$, respectively. Table 4 summarizes the DMA results of the triblock copolymers. As the pHEMA content is increased, storage modulus increased as well. However, copolymers with more PDMS had a lower storage modulus and higher $\tan \delta$, indicating a large loss of mechanical energy. The highest $\tan \delta$ was

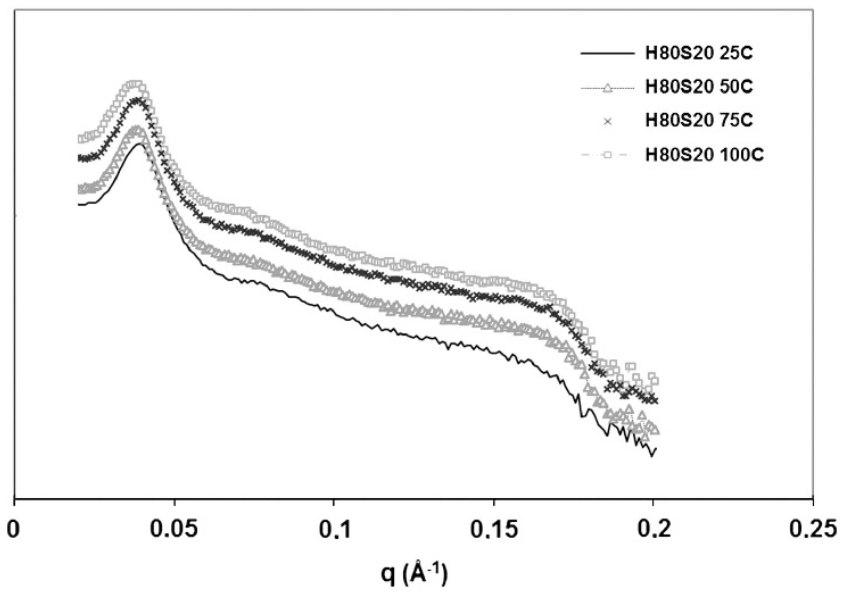

Figure 6 SAXS profiles of H80S2O as a function of temperature. A full color version of this figure is available at Polymer Journal online.

Table 4 Viscoelastic properties of triblock copolymers

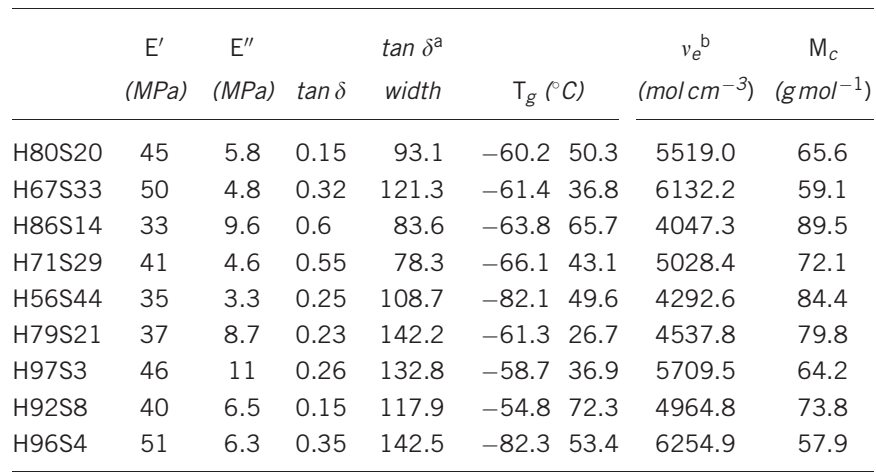

Abbreviations: $E^{\prime}$, storage modulus; $E^{\prime \prime}$, loss modulus; $M_{\mathrm{c}}$, molecular weight between crosslinks; $\tan \delta$, tangent loss; $T_{\mathrm{g}}$, glass transition temperature; $v_{e}$, crosslink density. aTan $\delta$ values are taken from the maximum points of transitions.

a Tan $\delta$ values are taken from the maximum points of transitions.
${ }^{b} \mathrm{~A}$ temperature of $60^{\circ} \mathrm{C}$ (the beginning of the rubbery plateau) was used to calculate the crosslink density and molecular weight between crosslinks because it is above the glass transition temperature.

observed in H71S29. When the miscibility of HEMA with PDMS increases, $\tan \delta$ broadens as a result of the abundant transitions. Triblock copolymers with high pHEMA contents, such as H97S3, had broad $\tan \delta$ transitions. This phenomenon was attributed to the high miscibility of pHEMA blocks with shorter PDMS blocks. ${ }^{34}$ This observation was in agreement with the SAXS profile of H97S3, which had primary reflection with a very low intensity.

In $\tan \delta$, two discrete transitions were observed at $\sim-55^{\circ} \mathrm{C}$ and $\sim 50^{\circ} \mathrm{C}$, which correspond to the melting temperature of $\mathrm{PDMS}^{30}$ and the glass transition temperature $\left(T_{\mathrm{g}}\right)$ of pHEMA, respectively. The $T_{\mathrm{g}}$ of the pHEMA homopolymer is $70^{\circ} \mathrm{C}$. The lower $T_{\mathrm{g}}$ of pHEMA in the triblock copolymers could be attributed to the increased mobility of tethered PDMS segments in pHEMA domains. The glass transition of the pHEMA block was very low in the copolymer (H97S3) despite it having the least PDMS. In contrast, $T_{\mathrm{g}}$ of the PDMS block was higher than that of the other block copolymers. This difference indicated better mixing between the pHEMA and PDMS blocks compared with the other block copolymers. This observation could be attributed to the diminished phase separation between pHEMA and PDMS due to the asymmetry between the block molecular weights. 

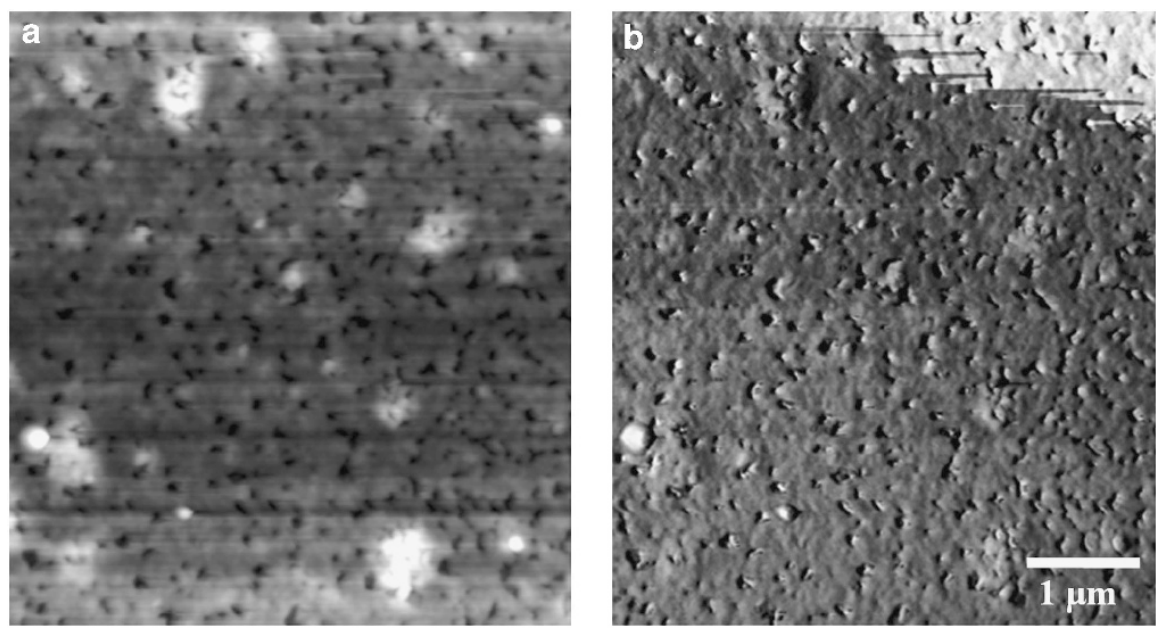

Figure 7 AFM tapping mode images for H67S33. (a) Height image of $5 \times 5 \mu \mathrm{m}$ with height scale of $50 \mathrm{~nm}$ and (b) phase image of $5 \times 5 \mu \mathrm{m}$ with phase scale of $0-20^{\circ}$. A full color version of this figure is available at Polymer Journal online.
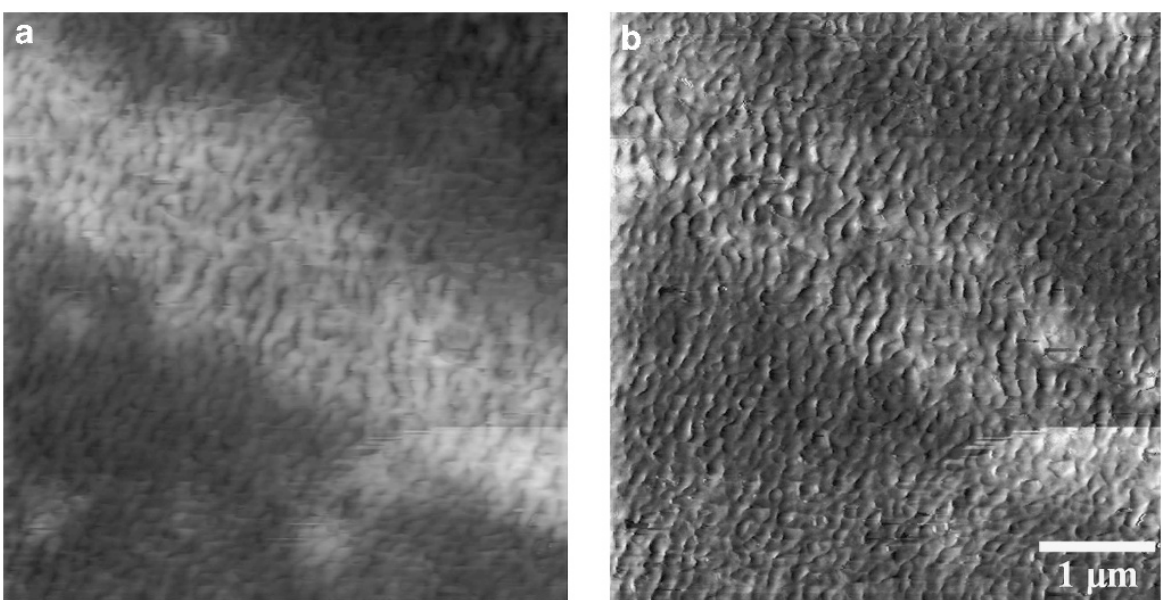

Figure 8 AFM tapping mode images for H56S44. (a) Height image of $5 \times 5 \mu \mathrm{m}$ with height scale of $50 \mathrm{~nm}$ and (b) phase image of $5 \times 5 \mu \mathrm{m}$ with phase scale of $0-20^{\circ}$. A full color version of this figure is available at Polymer Journal online.

H71S29, H56S44 and H79S21 had lower storage moduli than the other triblock copolymers, which could be attributed to the poor cooperation among pHEMA blocks due to larger distance between pHEMA endblocks. The copolymer, H96S4, showed the highest modulus owing to its large pHEMA composition. Additionally, pHEMA blocks in this copolymer likely formed a single polymer chain, therefore having a higher effective molecular weight. ${ }^{35}$ The symmetry between the pHEMA and PDMS blocks had an important role in determining the modulus of the polymer films. As the symmetry between the blocks increased (closer to the $M_{\mathrm{n}}$ of each block), the storage modulus increased and the loss modulus decreased. This behavior was validated for H67S33 and H97S3, the former having a theoretical $M_{\mathrm{n}}$ of 5000 and $3700 \mathrm{~g} \mathrm{~mol}^{-1}$ for pHEMA and PDMS, respectively, and the latter having a theoretical $M_{\mathrm{n}}$ of 15000 and $1400 \mathrm{~g} \mathrm{~mol}^{-1}$ for pHEMA and PDMS, respectively. However, as the amount of pHEMA (the segment with a greater $E^{\prime}$ (storage modulus)) increased, the storage modulus of the polymer film decreased. This observation indicates that symmetry had a more important role in determining the polymer mechanical characteristics than did the physical characteristics of the content.

\section{AFM analysis}

The morphology and phase separation behavior of the triblock copolymers were studied by AFM analysis. Three of the triblock copolymers with equal pHEMA molecular weights $\left(10000 \mathrm{~g} \mathrm{~mol}^{-1}\right)$ were selected to study the effect of PDMS block length on the overall morphology. Figure 7 shows an AFM image of H67S33 (5K-3.7K-5K). A clear phase separation was observed due to the symmetry between the molecular weights of pHEMA and PDMS. This observation was in agreement with the SAXS profile, which includes reflections at $q$ value ratios of 1:2:3 due to the presence of lamellae. Dark regions $(\sim 70 \mathrm{~nm}$ in diameter) are soft segments (PDMS), whereas the hard segments (pHEMA) appeared as bright regions in the height image due to their high modulus and friction. However, the soft segments in phase image appeared bright because low-energy siloxane segments have a higher affinity to the film-air interface than pHEMA segments.

Figure 8 shows the AFM image of H56S44 (5K-7.8K-5K). As expected from SAXS and DLS analyses, the chain inter-diffusion of blocks in H56S44 was hindered and almost 170-nm-diameter clusters were formed. Disordered spheres were obtained in this copolymer due to the solvent evaporation before the chains reached hydrodynamic 

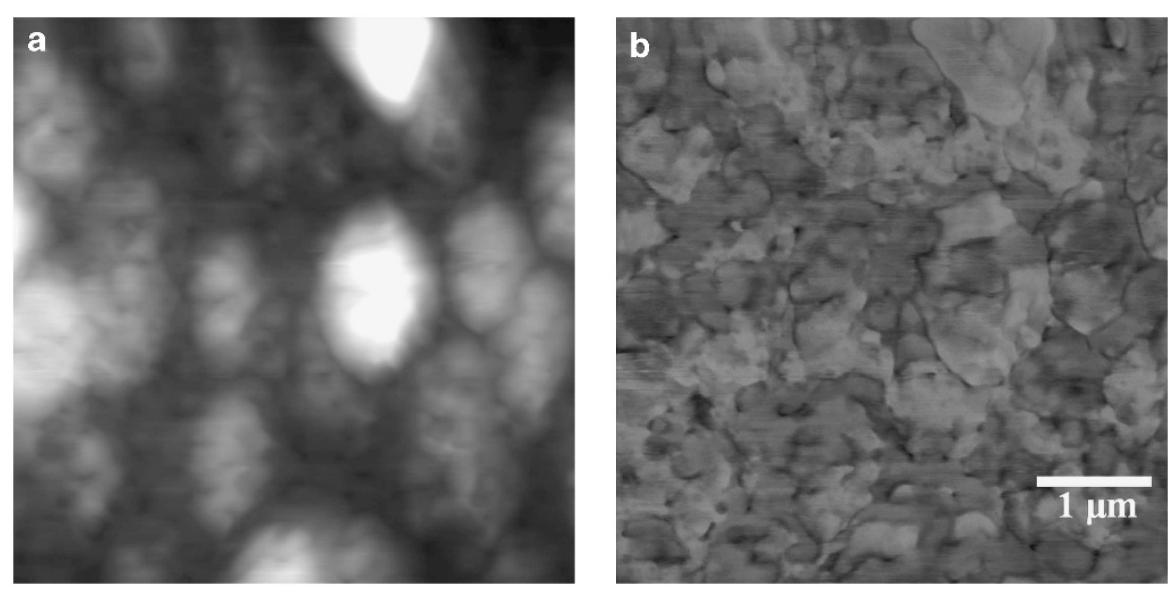

Figure 9 AFM tapping mode images for H92S8. (a) Height image of $5 \times 5 \mu \mathrm{m}$ with height scale of $50 \mathrm{~nm}$ and (b) phase image of $5 \times 5 \mu \mathrm{m}$ with phase scale of $0-20^{\circ}$. A full color version of this figure is available at Polymer Journal online.

equilibrium. This observation was supported by the SAXS profile of H56S44, in which a very broad primary reflection was observed, likely due to the randomly ordered structure.

Figure 9 shows the morphology of H92S8 (5K-1.4K-5K), in which no clear phase separation was observed. The H92S8 block copolymer exhibited a random island-like ${ }^{36}$ morphology because the film was cast in THF, which is a poor solvent for long pHEMA blocks. Therefore, the pHEMA blocks formed large bumps $(\sim 1 \mu \mathrm{m})$ on the soft segment domains. Two theories could be proposed to explain this observation: hydrogen bonds between pHEMA chains may have inhibited phase separation or very short PDMS blocks $\left(1400 \mathrm{~g} \mathrm{~mol}^{-1}\right)$ bridged between long end pHEMA blocks, slowing the phase separation. ${ }^{37}$ The morphology of H92S8 could be explained in similar fashions based on the SAXS profile. In this copolymer, the ordered structure was disrupted due to asymmetry between the pHEMA and PDMS blocks, which led to a high intensity primary reflection and a weak and broad shoulder at higher $q$.

\section{DISCUSSION}

Several issues motivated the study of amphiphilic acrylic-PDMS copolymers. Controlled free-radical polymerization of the hydrophilic monomer (HEMA) using hydrophobic macroinitiators (PDMS) was performed to synthesize block copolymers with varying molecular weights of pHEMA blocks. Additionally, the influence of block length on several parameters, such as micellar formation, phase miscibility and mechanical properties, was studied because these properties are functions of solubility parameters, the volume of each phase, the monomer type, and the modulus of each block.

Amphiphilic molecules can self-assemble into a rich diversity of organized structures, such as micelles and reverse micelles in polar and non-polar solvents, respectively. Additionally, vesicles, microemulsion and lyotropic crystals can be formed in selective solvents. In this study, reverse micelles obtained in THF yielded smaller particles than micelles in methanol. This observation allows the particle size to be controlled for some applications, such as nanoparticle synthesis. The particle size of the triblock copolymers also depended on the ratio of hydrophobic/ hydrophilic content. As the amount of PDMS increased in triblock copolymers, the micelle size in methanol also increased, indicating more triblock copolymers in aggregates. When the block length of PDMS increased, the size of reverse micelles in THF increased.

The present study reports the preparation of a new hybrid block copolymer with both hydrophilic and hydrophobic segments and a combination of hard (pHEMA) and soft (PDMS) segments. Therefore, it was exciting to prepare these hybrid triblock copolymers with varying amount of each phase to adjust mechanical properties. Higher amount of PDMS segment generally decreased modulus and crosslink density of the triblock copolymers. Storage modulus of some triblock copolymers was independent of the composition and molecular weight. Although H80S20 and H79S21 have similar amounts of pHEMA and PDMS, H79S21 (higher $M_{\mathrm{n}}$ ) exhibited a lower storage modulus than H80S20 (lower $M_{\mathrm{n}}$ ) in the rubbery plateau. The PDMS (H79S21) block's much higher molecular weight reduced the cooperative motion between pHEMA blocks and led to a lower effective molecular weight of pHEMA. ${ }^{35}$

Controlling the nanostructure of heterogeneous materials is very important for determining mechanical properties. If self-assembly can be obtained in a heterogeneous system, the system nanostructure can be determined. The self-assembly of the triblock copolymer depended on the block length in this study. Phase immiscibility of the triblock copolymers was favored when the blocks were symmetrical. Lamellae formation was obtained for H67S33 (5K-3.7K-5K). When the blocks are asymmetric, phase separation was hindered and a disordered sphere morphology was observed. This finding could be attributed to the compensation of the repulsion between pHEMA and PDMS by entropy. The triblock copolymer (H56S44, 5K-7.8K-5K) resulted in a disordered sphere morphology due to the compensation of repulsion by entropy and kinetically limited diffusion.

\section{CONCLUSIONS}

A series of pHEMA- $b$-PDMS- $b$-pHEMA amphiphilic triblock copolymers was prepared by ATRP in this study. The GPC and NMR results showed that the polymerization resulted in copolymers with a PDI of approximately 1.5 due to either use of macroinitiators with broad PDI or loss of terminal groups during polymerization. The NMR study confirmed micelle formation in methanol or methanolwater, whereas reverse micelles were formed in THF. In DLS and TEM, the micellar diameter increased with greater lengths of hydrophobic and/or hydrophilic blocks. The $T_{\mathrm{g}}$ of $\mathrm{pHEMA}$ was lower than expected due to the partial miscibility of pHEMA in PDMS domains. Phase separation was observed by AFM when the block lengths of amphiphilic copolymers were symmetric. However, the phase separation diminishes when the block molecular weights are asymmetric despite the large difference between the solubility parameters of pHEMA and PDMS. 
1 Soni, S. S., Sastry, N. V. \& George, J. Dynamic light scattering and viscosity studies on the association behavior of silicone surfactants in aqueous solutions. J. Phys. Chem. B. 107,5382 (2003)

2 Freij-Larsson, C., Nylander, T., Jannasch, P. \& Wesslen, B. Adsorption behaviour of amphiphilic polymers at hydrophobic surfaces: effects on protein adsorption. Biomaterials 17, 2199 (1996).

3 Xu, J., Bohnsack, D. A., Mackay, M. E. \& Wooley, K. L. Unusual mechanical performance of amphiphilic crosslinked polymer networks. J. Am. Chem. Soc. 129, 506 (2007).

4 Bruns, N., Scherble, J., Hartmann, L., Thomann, R., Ivan, B., Mulhaupt, R. \& Tiller, J. C. Nanophase separated amphiphilic conetwork coatings and membranes. Macromolecules 38, 2431 (2005)

5 Kimerling, A. S. \& Bhatia, S. R. Block copolymers as low-VOC coatings for wood: characterization and tannin bleed resistance. Prog. Org. Coat 51, 15 (2004).

6 Amado, E., Augsten, C., Mader, K., Blume, A. \& Kressler, J. Amphiphilic water soluble triblock copolymers based on poly(2,3-dihydroxypropyl methacrylate) and poly(propylene oxide): synthesis by atom transfer radical polymerization and micellization in aqueous solutions. Macromolecules 39, 9486 (2006).

7 Yun, J., Faust, R., Szilagyi, L. Sz., Keki, S. \& Zsuga, M. Effect of architecture on the micellar properties of amphiphilic block copolymers: comparison of $A B$ linear diblock, A1A2B, and A2B heteroarm star block copolymers. Macromolecules 36, 1717 (2003).

8 Remant Bahadur, K. C., Bhattarai, S. R., Aryal, S, Khil, M. S., Dharmaraj, N. \& Kim, H. Y. Novel amphiphilic triblock copolymer based on PPDO, PCL, and PEG: Synthesis, characterization, and aqueous dispersion. Colloids Surf. A: Physicochem. Eng. Aspects 292, 69 (2007)

9 Wang, S. F., Lu, L. C., Gruetzmacher, J. A., Currier, B. L. \& Yaszemski, M. J. A biodegradable and cross-linkable multiblock copolymer consisting of poly(propylene fumarate) and poly( $\varepsilon$-caprolactone): synthesis, characterization, and physical properties. Macromolecules 38, 7358 (2005).

10 Bae, Y. H., Huh, K. M., Kim, Y. \& Park, K. H. Biodegradable amphiphilic multiblock copolymers and their implications for biomedical applications. J. Controlled Release 64, 3 (2000).

11 Chen, Y. H. \& Yang, C. P. Coemulsion and electrodeposition properties of mixtures of cationic epoxy resin and cationic acrylic resin containing blocked-isocyanate groups. J. Appl. Polym. Sci 51, 1539 (1994).

12 Pellice, S. A., Fasce, D. P. \& Williams, R. Development of a bilayer coating to improve the adhesion between stainless steel and in situ-polymerized poly(methyl methacrylate). J. Appl. Polym. Sci. 105, 2351 (2007).

13 Kucukoglu, E., Acar, I., Iyim, T. B. \& Ozgumus, S. A novel type of Si-containing acrylic resins: synthesis, characterization, and film properties. J. Appl. Polym. Sci. 104, 3324 (2007).

14 Hill, R. M. in Encyclopedia of Physical Science and Technology. (ed. Meyers, R. A.). 3rd edn, vol 14, 40 (Academic Press, San Diego, CA, 2002).

15 Lazzari, M., Liu, G. \& Lecommandoux, S. Block Copolymers in Nanoscience: Block Copolymers in Nanoscience. 391 (Wiley-VCH, Weinheim, 2006).

16 Muhlebach, A, Gaynor, S. G. \& Matyjaszewski, K. Synthesis of amphiphilic block copolymers by atom transfer radical polymerization (ATRP). Macromolecules 31, 6046 (1998).

17 Beers, K. L., Boo, S., Gaynor, S. G. \& Matyjaszewski, K. Atom transfer radical polymerization of 2-hydroxyethyl methacrylate. Macromolecules 32, 5772 (1999).

18 Wang, J. S. \& Matyjaszewski, K. Controlled/“Living” radical polymerization. halogen atom transfer radical polymerization promoted by a $\mathrm{Cu}(\mathrm{I}) / \mathrm{Cu}(\mathrm{II})$ redox process. Macromolecules 28, 7901 (1995).
19 Duxin, N., Liu, F., Vali, H. \& Eisenberg, A. Cadmium sulphide quantum dots in morphologically tunable triblock copolymer aggregates. J. Am. Chem. Soc. 127, 10063 (2005).

20 Zhang, L., Niu, H., Chen, Y., Liu, H. \& Gao, M. Preparation of platinum nanoparticles using star-block copolymer with a carboxylic core. J. Colloid Interface Sci. 298, 177 (2006).

21 Duquesne, E., Habimana, J., Degee, P. \& Dubois, P. Synthesis of silicone-methacrylate copolymers by ATRP using a nickel-based supported catalyst. Macromol. Chem. Phys. 207, 1116 (2006).

22 Miller, P. J. \& Matyjaszewski, K. Atom transfer radical polymerization of (Meth)acrylates from poly(dimethylsiloxane) macroinitiators. Macromolecules 32, 8760 (1999).

23 Dai, S., Ravi, P., Leong, C. Y., Tam, K. C. \& Gan, L. H. Synthesis and aggregation behavior of amphiphilic block copolymers in aqueous solution: Di- and triblock copolymers of poly(ethylene oxide) and poly(ethyl acrylate). Langmuir 20, 1597 (2004).

24 Otsu, T. \& Yoshida, M. Role of initiator-transfer agent-terminator (iniferter) in radical polymerizations: Polymer design by organic disulfides as iniferters. Makromol. Chem. Rapid Commun. 3, 127 (1982).

25 Otsu, T., Yoshida, M. \& Tazaki, T. A model for living radical polymerization. Makromol. Chem. Rapid Commun. 3, 133 (1982).

26 Matyjaszewski, K., Patten, T. \& Xia, J. Controlled/“Living” radical polymerization. kinetics of the homogeneous atom transfer radical polymerization of styrene. J. Am. Chem. Soc. 119, 674 (1997)

27 Lee, S. C., Chang, Y. K., Yoon, J. S., Kim, C. H., Kwon, I. C., Kim, Y. H. \& Jeong, S. Y. Synthesis and micellar characterization of amphiphilic diblock copolymers based on poly(2-ethyl-2-oxazoline) and aliphatic polyesters. Macromolecules 32, 1847 (1999).

28 Yuan, J., Xu, Z., Heng, S. \& Feng, L. The aggregation of polystyrene-b-poly(ethylene oxide)-b-polystyrene triblock copolymers in aqueous solution. Eur. Polym. J. 38, 1537 (2002).

29 Dingenouts, N. \& Ballauff, M. First stage of film formation by latexes investigated by small-angle X-ray scattering. Langmuir 15, 3283 (1999).

30 Sheth, J. P., Yilgor, E., Erenturk, B., Ozhalici, H., Wilkes, G. L. \& Yilgor, I. Structureproperty behavior of poly(dimethylsiloxane) based segmented polyurea copolymers modified with poly(propylene oxide). Polymer 46, 8185 (2005).

31 Bendejacq, D., Ponsinet, V., Joanicot, M., Loo, Y.-L. \& Register, R. A. Well-ordered microdomain structures in polydisperse poly(styrene)-poly(acrylic acid) diblock copolymers from controlled radical polymerization. Macromolecules 35, 6645 (2002).

32 Seitz, M. E., Burghardt, W. R., Faber, K. T. \& Shull, K. R. Article self-assembly and stress relaxation in acrylic triblock copolymer gels. Macromolecules 40, 1218 (2007).

33 Caykara, T., Ozyurek, C., Kantoglu, O \& Guven, O. Influence of gel composition on the solubility parameter of poly(2-hydroxyethyl methacrylate-itaconic acid) hydrogels. J. Polym. Sci. Part B Polym. Phys 40, 1995 (2002).

34 Ruzette, A. V., Tence-Girault, S., Leibler, L., Chauvin, F., Bertin, D., Guerret, 0. \& Gerard, P. Molecular disorder and mesoscopic order in polydisperse acrylic block copolymers prepared by controlled radical polymerization. Macromolecules 39, 5804 (2006).

35 Han, C. D., Baek, D. M., Kim, J. K. \& Chu, S. G. Rheological behaviour of block copolymers in the disordered state: effects of molecular weight and block length ratio. Polymer 33, 294 (1992).

$36 \mathrm{Wu}$, N., Zheng, A., Huang, Y. \& Liu, H. Morphology of poly(styrene-block-dimethylsiloxane) copolymer films. J. Appl. Polym. Sci. 104, 1010 (2007).

37 Dai, B., Song, M., Hourston, D. J., He, X., Liang, H. \& Pan, C. Influence of block lengths and symmetries of block copolymers on phase behavior of polymer A/polymer B/block copolymer ternary blends. Polymer 45, 1019 (2004). 